\title{
Student Evaluations Of Online Classes Versus On-Campus Classes
}

Karen A. Loveland, (E-mail: loveland@mscd.edu), Metropolitan State College of Denver John P. Loveland, (E-mail: jlovelan@nmsu.edu), New Mexico State University

\begin{abstract}
Some schools have reported that student evaluations of teaching for online/Internet classes are significantly lower that the evaluations given for traditional/on-campus classes. While many institutions appear to use the same (or similar) rating forms for online and on-campus classes, some people question the validity of using forms designed for on-campus classes to evaluate online classes.

The authors of this paper contend that the same general characteristics of effective teaching apply equally to online and on-campus courses. However, students in online classes interpret these factors differently when evaluating the instructor (e.g., the relative importance of the instructor's oral versus written communication skills is different in online versus on-campus courses).

Specifically, this paper identifies ten factors that are frequently measured by student evaluation forms: (1) Knowledge of the Subject, (2) Communication Skills/Ability, (3) Enthusiasm for the Subject, (4) Encouragement of Student Participation, (5) Rapport with Students, (6) Fairness in Grading, (7) Timeliness in Providing Feedback, (8) Organization of Class, (9) Adequacy of Textbook and Other Learning Materials, and (10) Instructor's Preparation for Class. The paper then discusses the differences between how online and on-campus students may interpret these factors when completing student evaluations. The paper concludes with suggestions for improving student evaluations of online classes.
\end{abstract}

\section{Introduction}

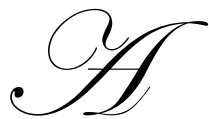

ccording to the National Center for Education Statistics (NCES) of the U.S. Department of Education (USDE), almost $44 \%$ of all higher education institutions offered distance education courses in 1997. Furthermore, the NCES report indicated that business schools were more likely to offer distance education courses than most other academic units (U.S, Department of Education, 1999).

While the NCES study focused on the broadest definition of distance education, the report and other more recent studies indicates that there has been an explosion of Internet-based distance courses in the past few years. Faurer (2000) suggests that, at some "progressive institutions", the numbers of students enrolled in online classes may soon rival the enrollment numbers for traditional/on-campus classes.

The explosive growth in the number of online classes poses some new challenges for academicians including difficulties hiring faculty with online teaching interests and experience, increases in costs associated with technology, training and faculty incentives, and problems associated with the comparison of traditional and online teaching in terms of workload, compensation, and evaluation. Specifically, anecdotal evidence suggests that there are significant differences in student evaluations of teaching effectiveness between traditional/on-campus classes and online classes.

Readers with comments or questions are encouraged to contact the authors via email. 
Student evaluations of teaching are important to faculty for two primary reasons. First, student evaluations provide data that is frequently used for administrative decisions such as tenure, promotion, and salary increases. Second, teaching evaluations provide feedback to help faculty improve future teaching performance (Sheehan and DuPrey, 1999).

Despite the importance of student evaluations of teaching, it appears that many institutions haven't developed and validated student evaluation instruments for use in online classes. Many institutions simply use the same form used in on-campus classes to evaluate online classes. Other institutions make slight modifications to the form to reflect obvious differences in online and traditional delivery methods. For example, at one institution, the traditional student evaluation form included the criterion, "instructor's oral communication skills"; this phrase was changed to, "instructor's written communication skills" for the online class evaluation form.

The use of evaluation forms designed for on-campus classes to evaluate online classes has given rise to significant concerns that online teaching may affect faculty negatively in terms of administrative decisions. Some institutions report that student evaluation ratings for online classes are significantly lower than the ratings given in oncampus classes. For example, one large mid-western college uses similar forms for student evaluation of on-campus and over 100 online classes each semester. This institution calculates separate mean scores for student evaluations of overall teaching effectiveness for online and on-campus classes. These mean scores are consistently twenty percent lower for online classes. In addition, some faculty at this institution report that student evaluations of their online classes are up to one full point lower (on a 6-point scale) than evaluations of the identical classes they teach in the classroom.

These differential results have prompted some online faculty to suggest that the criteria used to measure teaching effectiveness in on-campus classes aren't relevant to online teaching. They further suggest that institutions need to reevaluate the operational definitions of teaching effectiveness and develop new student evaluation forms specifically designed to measure teaching effectiveness in online classes. The authors of this paper contend that the criteria measured by traditional student evaluation forms are not the cause of the observed difference in scores. In fact, the authors believe that the same general criteria for effective teaching apply equally to online and on-campus classes. However, the faculty behaviors and characteristics that students consider when assigning a rating for each criterion differ significantly between online and on-campus classes. Thus, it is important for online faculty to understand how online students might interpret and assess the major criteria for effective teaching.

In the next section of this paper, the authors identify ten factors that are commonly measured by traditional student evaluation forms and include a discussion of the faculty behaviors and characteristics that students evaluate when assigning ratings for each factor. The authors then discuss how student perceptions and expectations might differ when students assign ratings for the same ten factors in an online class. The paper concludes with suggestions online faculty can use to improve student evaluation results by adapting their teaching style to the expectations and perceptions of online students.

\section{Factors Affecting Student Evaluations in Traditional Classes}

Based on a review of selected articles related to student evaluations (e.g., Sheehan and DuPrey, 1999) and 50 years of combined teaching experience at a variety of educational institutions, the authors of this paper identified ten factors that are commonly measured on student evaluation forms. These factors are typically assumed to affect some global measure of overall teaching effectiveness and are often included in the evaluation instrument to explain differential ratings for the overall measure. For example, a one institution, the student evaluation instrument asks students to rate instructors on two global measures: effectiveness in teaching the subject and contribution to the course. The instrument then asks students to rate instructors on specific criteria (e.g., communication ability, rapport with students) that directly influence the overall ratings. Faculty are then encouraged to use this feedback to make specific changes to their teaching style/behaviors to address deficiencies in these ten areas. This in turn is expected to improve the global ratings used for administrative decisions. 
Table 1 identifies the ten factors and provides a brief outline of the instructor characteristics/behaviors associated with each of these factors in a traditional class.

\begin{tabular}{|c|c|}
\hline \multicolumn{2}{|c|}{ Table 1: Factors Affecting Student Evaluations In On-Campus/Traditional Classes } \\
\hline Factor & $\begin{array}{l}\text { Faculty Behaviors/Characteristics } \\
\end{array}$ \\
\hline Knowledge of the Subject & $\begin{array}{l}\text { - } \\
\text { - } \quad \text { Ubility to answer student questions in class } \\
\text { - } \quad \text { Consistency/compatibility of information provided with other information } \\
\text { sources (e.g., other faculty, news sources) }\end{array}$ \\
\hline Communication Skills/Ability & $\begin{array}{l}\text { - Clarity of verbal communication including vocabulary, audibility, speaking } \\
\text { inflection, rhythm, pace } \\
\text { - Ability to adjust communication in response to non-verbal cues sent by } \\
\text { students during lectures }\end{array}$ \\
\hline Enthusiasm for the Subject & $\begin{array}{l}\text { - Verbal inflection and tone } \\
\text { Facial expressions and body language } \\
\text { Relating personal examples that demonstrate how instructor uses/applies } \\
\text { course topics } \\
\text { Use of humor } \\
\text { Use of props (e.g., music, videos, etc...) to demonstrate that instructor } \\
\text { enjoys teaching the class }\end{array}$ \\
\hline Encouragement of Student Participation & 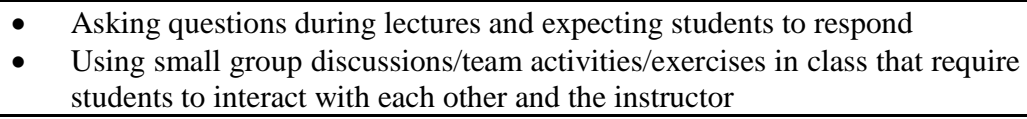 \\
\hline Rapport with Students & $\begin{array}{l}\text { - } \quad \text { Largely based on face-to-face interactions with students } \\
\text { - } \quad \text { Ability to remember students' names and other personal details } \\
\text { - Tailoring lectures and assignments to individual needs/interests of students } \\
\text { - } \quad \text { Available before and after class to discuss individual concerns } \\
\text { - Sincere compliments/comments on students' lives to indicate interest in } \\
\text { each student (e.g., "nice tie", "is your grandmother feeling better", "congra- } \\
\text { tulations on your award/win/etc.") }\end{array}$ \\
\hline Fairness in Grading & $\begin{array}{l}\text { - Students compare grades assigned to other students. } \\
\text { - } \quad \text { Explaining grading criteria and common errors/mistakes in each assign- } \\
\text { ment during class time } \\
\text { - Justifying expectations during class time } \\
\text { - Willingness to reevaluate grades }\end{array}$ \\
\hline Timeliness in Providing Feedback & $\begin{array}{l}\text { - Instructor controls when assignments are submitted (e.g., when instructor } \\
\text { picks up assignments). } \\
\text { - Return graded work by the next class period. No more than seven to ten } \\
\text { days for "major" assignments (e.g., essay exam, term paper) } \\
\text { - Answer student questions in class or by beginning of next class period } \\
\text { when additional investigation required } \\
\text { - Reply to voice mail, notes and other "out of class" student messages within } \\
\text { two to three days }\end{array}$ \\
\hline Organization of the Class & $\begin{array}{ll}\text { - } & \text { Learning materials have a "logical flow" } \\
\text { - } & \text { Providing a detailed schedule AND sticking to the schedule } \\
\text { - } & \text { Order in which material presented controlled by instructor; tends to be li- } \\
\text { near. }\end{array}$ \\
\hline $\begin{array}{l}\text { Adequacy of the Textbook and Other } \\
\text { Learning Materials }\end{array}$ & $\begin{array}{ll} & \text { Textbook provides a suitable outline of course materials } \\
\text { - } & \text { Providing/identifying supplemental resources } \\
\text { - } & \text { Providing detailed handouts when necessary } \\
\end{array}$ \\
\hline Instructor's Preparation for Class & $\begin{array}{l}\text { - } \begin{array}{l}\text { Adhering to scheduled start time, end time and topic for each class session } \\
\text { - Having necessary materials available at the beginning of each class session } \\
\text { (e.g., textbook, handouts, graded assignments) }\end{array} \\
\end{array}$ \\
\hline
\end{tabular}


Student evaluations of each of the factors in Table 1 tend to emphasize the students' perceptions of the faculty based on face-to-face interactions. In addition, the relative importance of the textbook and other materials written by other people tend to be less important than the information communicated by the instructor during lectures and other contacts with students. Specifically, students' perceptions of teaching effectiveness tend to be greatly affected by the instructor's ability to manage the classroom experience and deliver an effective lecture.

\section{Differences Between Student Perceptions in Online and On-campus Classes}

The authors of this paper contend that the ten factors identified in the previous section are equally important to global evaluations of teaching effectiveness in online classes. However, what differs are the ways in which students may interpret each of these factors and the specific faculty behaviors/characteristics they consider when assigning ratings.

Table 2 provides a brief outline of the most significant differences between online and on-campus classes in terms of how faculty behaviors/characteristics may influence student evaluations of the ten factors.

\begin{tabular}{|c|c|}
\hline Factor & Faculty Behaviors/Characteristics \\
\hline Knowledge of the Subject & $\begin{array}{l}\text { - } \quad \text { Based more on written communication skills than verbal ability } \\
\text { Instructor doesn't have as many opportunities to demonstrate knowledge } \\
\text { by answering questions or, providing "off the cuff" examples } \\
\text { Easier for students to evaluate consistency and compatibility with other } \\
\text { sources because written communication provides a permanent record } \\
\text { Students may be more likely to notice the age of information you share } \\
\text { and the Internet conditions us to expect the most current information } \\
\text { available. }\end{array}$ \\
\hline Communication Skills/Ability & $\begin{array}{l}\text { - Verbal skills unimportant...non-verbal skills less important } \\
\text { - Writing skills/ability critical. Writing errors including spelling, grammar, } \\
\text { and sentence construction may have significant impact on student ratings }\end{array}$ \\
\hline Enthusiasm for the Subject & $\begin{array}{l}\text { - } \quad \text { Relies on writing style as opposed to verbal/non-verbal cues. } \\
\text { Less opportunity to demonstrate enthusiasm with activities, examples, } \\
\text { props } \\
\text { - } \quad \text { Humor more likely to backfire }\end{array}$ \\
\hline Encouragement of Student Participation & $\begin{array}{l}\text { More difficult to encourage student participation without face-to-face con- } \\
\text { tact (e.g., can't ask questions in real-time and wait for response) } \\
\text { Tends to be based more on individual communications rather than com- } \\
\text { munication with the entire class/group. }\end{array}$ \\
\hline Rapport with Students & $\begin{array}{l}\text { - } \\
\text { - Students carry more responsibility for relationship development (e.g., they } \\
\text { must read the material/messages you provide). } \\
\text { Evaluations more a function of personalization of class materials and } \\
\text { communication. }\end{array}$ \\
\hline Fairness in Grading & $\begin{array}{l}\text { - } \quad \text { Based less on comparison of grades with other students. } \\
\text { Tend to base fairness estimates on amount of effort expended to complete } \\
\text { assignment instead of the results they achieved relative to other students. } \\
\text { - Lower tolerance for competitive/comparative grading } \\
\text { More difficult to assess equity in enforcement of policies (e.g., late poli- } \\
\text { cies) because they don't hear/see communications with other students. }\end{array}$ \\
\hline Timeliness in Providing Feedback & $\begin{array}{l}\text { - Students may submit assignments at any time; students have more control } \\
\text { over date/time of submissions. } \\
\text { Better/more motivated students may wait longer for grades if they submit } \\
\text { assignments early. } \\
\text { - } \quad \text { Grading and communication delays may be based on technical problems }\end{array}$ \\
\hline
\end{tabular}




\begin{tabular}{|c|c|}
\hline Factor & $\begin{array}{r}\text { Faculty Behaviors/Characteristics } \\
\end{array}$ \\
\hline & $\begin{array}{l}\text { that aren't apparent to students. } \\
\text { Instructor can't control when students check e-mail or log into class which } \\
\text { may affect student perceptions of timeliness. } \\
\text { The Internet conditions people to expect immediate response to communi- } \\
\text { cation; this may affect student perceptions in online classes }\end{array}$ \\
\hline Organization of the Class & $\begin{array}{l}\text { Order of presentation of material controlled more by students than instruc- } \\
\text { tor; access to material may be non-linear. } \\
\text { May be affected by factors related to the design of the class Web pag- } \\
\text { es/site; ease of navigation, speed of page loading, use of common naviga- } \\
\text { tion elements, etc. can affect ratings. } \\
\text { - Writing style (organization) may also affect ratings. }\end{array}$ \\
\hline $\begin{array}{l}\text { Adequacy of the Textbook and Other } \\
\text { Learning Materials }\end{array}$ & $\begin{array}{l}\text { Adequacy of textbook tends to be more important; students rely more } \\
\text { heavily on textbook since they can't hear lectures; textbook needs to an- } \\
\text { swer more of their questions, be easier to read, and more compatible with } \\
\text { online pedagogy. } \\
\text { Quantity/amount of other learning materials provided by instructor may } \\
\text { have significant impact on this rating. } \\
\text { - Writing style (clarity, easy to follow) may affect ratings. }\end{array}$ \\
\hline Instructor's Preparation for Class & $\begin{array}{l}\text { - Students may have a self-paced mentality. They may expect to be able to } \\
\text { work ahead when they have time. } \\
\text { Instructor doesn't know when students will be ready to start on new ma- } \\
\text { terial/assignments } \\
\text { Many students expect material to be available at least two weeks before } \\
\text { scheduled start date. } \\
\text { - Some course management systems based new class material on material } \\
\text { copied from previous semesters; need to have all material updated at the } \\
\text { beginning of the semester or deny access to material that isn't updated; } \\
\text { students that work ahead may reduce preparation ratings for instructors } \\
\text { that change material after they have viewed it. }\end{array}$ \\
\hline
\end{tabular}

Because of the lack of regular class meetings, students' perceptions of teaching effectiveness tend to be influenced by evaluations of different behaviors/characteristics in online classes. The instructor's writing skills/abilities can influence ratings of several factors including adequacy of the textbook, knowledge of the subject, and rapport with students. In addition, students may not be able to distinguish between problems created by instructor mistakes and those created by the technology. For example, if an online quiz isn't available when a student is ready to take it, the student may count it against the instructor in terms of "preparation for class" even if the true cause of the problem was a temporary technical failure on the part of the course management software.

\section{Suggestions for Improving Student Evaluations in Online Classes}

Given the differences in student perceptions of teaching effectiveness outlined above, instructors that want to improve their teaching evaluations need to adapt their teaching style and behaviors to the unique requirements of the online environment. The following paragraphs provide some specific suggestions for improving student ratings of each of the ten factors discussed in the previous sections of this paper.

Knowledge of the Subject -- Improving "knowledge of subject" ratings involves creating opportunities for the instructor to demonstrate his or her knowledge to students. Possible actions include:

- Using live chats to give students the opportunity to experience the instructor's ability to "think on his/her feet". Being able to respond quickly to questions as they arise in a real-time setting should improve student perceptions of instructor knowledge. 
- Devoting more time to reviewing current literature, news, etc... and sharing this information with students regularly. Make sure you're providing the most current examples/statistics to students. If students can find something that you didn't communicate or worse, something that contradicts something you share, it could decrease your knowledge ratings.

- $\quad$ Being especially careful about the accuracy of the information you present. Because written communication provides a permanent record, it is easier for students to compare what you say to what they hear on the news and in other classes. Encourage students to discuss discrepancies with you in a public forum to demonstrate additional knowledge.

Communication Skills/Ability -- Improving "communication skills" ratings potentially has the greatest impact on overall ratings of teaching effectiveness in online classes. Writing ability can affect student perceptions of instructor knowledge, preparation, professionalism, and rapport. All other things being equal, instructors that write well should receive higher student evaluations that those that aren't strong writers. Suggestions to help improve your ratings include:

- Devoting more attention to writing style and presentation. Use spelling/grammar check to identify grammar, sentence construction, and other errors in your writing. Become more familiar with your writing weaknesses and pay special attention to those areas when you prepare online class materials and communicate with students.

- Having colleagues/friends proofread your online class materials before you make them available to students. Ask for feedback on clarity of writing, organization, and understandability. Advocate the idea that schools should provide writing assistance/professional editors for online class material.

- $\quad$ Being especially careful with "off-the-cuff" writing (e.g., discussion group/forum, e-mail). Use spell-check when available... when it isn't available, prepare comments offline using word processing software then copy/paste comments into the messages you send.

Enthusiasm for the Subject -- Improving "enthusiasm" ratings involves finding new ways to communicate with students. The lack of face-to-face contact makes it difficult for students to evaluate this factor when they assign ratings; they can't base their evaluation on the instructor's tone of voice, facial expressions, and other non-verbal cues. Instead, they are likely to base their evaluation on the instructor's writing style and the type of information the instructor shares with them. They could also assign lower ratings to instructors they perceive as "too formal" since the overly formal communication may come across as dry or uninteresting. Suggestions for improving your ratings include:

- $\quad$ Using current/real-time examples to demonstrate that you enjoy applying your knowledge of the subject. Make it clear to students that you keep up on the current literature by sharing links to articles, quotes, etc... with them on a regular basis.

- $\quad$ Providing more detail in written responses to student questions/comments. For example, if a student makes a comment on a topic in the discussion group, replying with "I agree" doesn't demonstrate as much enthusiasm as a response that explains why you agree or provides additional supporting information.

- $\quad$ Sharing personal examples to illustrate course concepts. For example, when you're covering consumer behavior in your class, post a message on the class forum or send an e-mail message to the mailing list that tells students a story about a recent purchase and how your marketing knowledge made you a better consumer.

- Write actively. Avoid passive voice, long lead-ins and other writing style "errors" that make your writing overly formal or boring.

Encouragement of Student Participation -- students in online classes sometimes report feelings of isolation that can affect their evaluation of the encouragement the instructor provided. In addition, they often feel that they are solely responsibility for controlling their level and frequency of participation. In an online class, instructors need to make obvious attempts to encourage participation to ensure students notice those efforts when they assign ratings. Some suggestions include: 
- $\quad$ Encouraging students to communicate with you on a regular basis. Sending deadline reminders via e-mail, contacting students that fail to complete an assignment, and offering individualized suggestions for class participation on a weekly basis makes students feel more "connected" to you and to the class. This should improve their motivation for participation and your ratings for encouragement.

- Using team projects to encourage students to interact with each other. Team projects make students feel less isolated and condition them to share information with their classmates. Requiring regular contact for the purpose of a specific project should have the side effect of increasing student-to-student communication about other aspects of the class.

- $\quad$ Assigning a specific participation grade for contributions to class discussions (e.g., mailing list, threaded discussion group, chat, etc...) that constitutes a significant portion of the student's final grade in the class. Instructors should note that evaluation of online class participation grades is usually easier and more "objective" than assigning participation grades in on-campus classes. The medium allows you to keep a permanent record of the quantity, frequency, and quality of each student's contribution to class discussions. Thus, it is important to communicate your expectations to students in terms of these criteria. In addition, it often helps to give students specific suggestions for participation. For example, when students ask a question or share a story with you via e-mail (privately), a brief note that their question/story would be beneficial to other students (and a reminder that they would earn participation credit for sharing that information) can significantly improve student perceptions of the amount of encouragement you offered.

Rapport with Students -- the lack of personal contact in the classroom and the limited (if any) face-to-face contact instructors have with most online students outside of the classroom (e.g., during office hours), makes it difficult to establish rapport with students. Therefore, instructors need to make unusual efforts to discover and understand their students needs and interests. Specific suggestions include:

- $\quad$ Responding to all e-mail messages sent by students, even those messages that don't ask questions. By responding to all messages, you demonstrate that you're interested in what the students have to say. In addition, they don't have to wonder whether you received or read their messages.

- $\quad$ Complimenting students for individual achievements/contributions. Provide public compliments ("excellent point") on the messages they post in the discussion forum/group. In addition, a public thank you when a student points out a mistake or a problem with a course page (e.g., a broken link) helps build additional rapport with students.

- $\quad$ Collecting profile-type information from students at the beginning of the semester and identifying common interests/activities and individual needs/learning goals. Respond to each profile and share insights. Then personalize the course to individual student needs. For example, if you know that one student plays varsity football, find a way to work that into a discussion question, assignment or lecture.

Fairness in Grading -- because students in online classes seldom interact with other students, they don't have the same opportunities to compare and discuss the grades they receive for various assignments. Without this basis for comparison, students are more likely to base their evaluations of fairness on the time/effort they expended to complete an assignment rather than the relative quality of their work. Therefore, instructors need to develop strategies to encourage students to evaluate their own efforts more objectively. Some suggestions for improving your ratings include:

- Developing rubrics and other methods to standardize grading processes/feedback to ensure consistency in grading. Provide students with more information about grading expectations in the syllabus and assignment guidelines. Try to anticipate the questions students might ask if they were sitting in your classroom and provide answers to those questions before they arise.

- Encouraging students to discuss/compare assignments. Include such discussions in your calculation of class participation grades.

- $\quad$ Starting grade-related discussions on the class forum. The authors know of one instructor that creates a "fake student" in each class and posts questions about assignments, grades, and other issues in the class forum. The instructor then responds to those messages.

- $\quad$ Providing students with summary statistics and general comments for each assignment. Instructors often 
hold impromptu discussions of assignments (e.g. what they were looking for) when then hand back assignments in class. However, it takes a special effort to provide that information to online students. Try to identify common errors for each assignment to help students improve grades on future assignments.

Timeliness in Providing Feedback -- students in traditional classes expect to receive feedback at a specific time (e.g., at the beginning of class) and in a specific place (e.g., in the scheduled classroom). On the other hand, online students complete and submit assignments at many different times and from many different locations (e.g., from work). Additionally, many students that take online classes do most of the course work outside traditional classroom teaching times. These students need access to their instructors during these times. The variability in times and places can delay the delivery of feedback and affect the ratings instructors receive for "timeliness". Suggestions for improving your ratings include:

- Managing student expectations related to grading and other feedback. Inform students of your grading process/procedures (e.g., you don't start grading assignments until the deadline expires) and how long it normally takes you to return grades. Tell students when they can typically expect a response to e-mail messages (e.g., within 24 hours).

- $\quad$ Sticking to the policies you set (e.g., returning homework grades within 48 hours after the deadline).

- $\quad$ Keeping students informed about emergencies, technical failures, and other problems that cause deviations from normal expectations (e.g., conference travel).

- $\quad$ Informing students of the specific "place" where they'll find the feedback you provide. Using the same address for all your original messages and telling students how that might differ for replies to their messages. For example, if a student sends an e-mail message from work, your reply will go to that address.

- $\quad$ Modifying your "9 to 5" mentality. If you're only available Monday through Friday during normal business hours, you may receive lower evaluations from students that are only available to work on the course late at night or on weekends. Responding to student e-mail at least once each weekend and several nights a week may significantly increase your "timeliness" ratings.

Organization of Class -- in an on-campus class, ratings of this factor are mainly related to the way you present oral information to students. However, in an online class, instructor ratings may also depend on the structure and design of the online class material. In addition, instructors in online classes typically have much less flexibility when it comes to making changes to planned class activities and requirements without being perceived as disorganized (e.g., it is more difficult to change a posted assignment even before the scheduled start date because students may have already accessed the information). Suggestions for improving your ratings for "organization" include:

- $\quad$ Providing extensive navigation links (e.g., back to top, back to syllabus) in course Web pages. Make it easy for students to access the information they need from multiple "locations" in the course material.

- $\quad$ Linking pages together for faster loading and ease of navigation. Consider how to best break up large amounts of information into individual pages.

- $\quad$ Creating a consistent design for course pages. Consistency in design may be as simple as using the same layout for all related pages or using common icons/graphics to identify related pages (e.g., a "?" graph on all FAQ-type pages). You should also strive to ensure that your pages use a consistent font style and size so students can easily distinguish one of your pages from the other pages they might visit during the semester.

Adequacy of Textbook and Other Learning Materials -- the quality and readability of the textbook may not have a significant impact on student evaluations of overall teaching effectiveness in on-campus classes because instructors can address textbook weaknesses during lectures. However, because the textbook is the primary vehicle for conveying course information in an online class, overall instructor ratings may be greatly influenced by the choice of textbook. Thus, online faculty need to select textbooks more carefully to ensure readability, consistency, and thoroughness. In addition, the lack of verbal communication increases the importance of providing supplemental learning materials. Improving your ratings for this factor might involve:

- Developing extensive online lectures. In effect, online faculty should write what amounts to a supplemen- 
tal textbook for online classes that conveys the information they would normally deliver in classroom lectures.

- $\quad$ Providing a "hot links" page with links to additional sources of relevant information. The plethora of information available on the Internet conditions users to expect links to a variety of additional information sources.

- $\quad$ Using active/online textbooks. Some publishers have started offering "online" versions of textbooks that publish the supplements typically used in the classroom (e.g., video cases) on a Web site. Using these books should improve student satisfaction with course textbooks by providing unique material.

- Developing a "custom book" for online classes. Most existing textbook packages have deficiencies that may affect student satisfaction. However, many publishers allow faculty/institutions to develop a textbook by taking the best parts of many textbooks and combining them with other material. Creating a custom textbook for online classes would make it easier for faculty to avoid textbook-related problems.

Instructor's Preparation for Class -- instructors in on-campus classes have more flexibility in terms of preparation (e.g., they can dismiss class early, they can prepare a set of activities to use when they aren't prepared for a specific class session, etc...). On the other hand, it is virtually impossible to "wing it" when teaching an online class. Either the material is fully prepared when students want to access it or it isn't...there isn't a way for instructors to disguise a lack of preparation. In addition, preparing class materials at the last minute is more likely to cause mistakes (e.g., writing errors) that affect ratings for other factors (e.g., communication ability). Suggestions for improving your "preparation" ratings include:

- $\quad$ Preparing materials for entire term before it begins. Because of the self-paced mentality of online classes, some students expect to be able to review the entire class at the beginning of the semester.

- $\quad$ Striving to stay at least two weeks ahead of students. Students often take online classes because of schedule conflicts and other problems that make adhering to a traditional schedule difficult. For example, a student may take an online class because he/she is planning an extended vacation during the term. By staying ahead of those students, you accommodate their need for flexibility.

- Keeping students informed of deviations from the normal schedule for posting material. If students expect you to post the next set of assignments at least one week before the "start date", you should inform them when you are unable to do so and let them know when the material will be available. Even worse, if something isn't available on the scheduled starting date (e.g., a quiz), you should inform students when they can expect to find it so they don't waste their time checking for the information every few hours/days.

\section{Summary and Conclusions}

This paper identified ten factors that affect overall student evaluations of teaching effectiveness: (1) Knowledge of the Subject, (2) Communication Skills/Ability, (3) Enthusiasm for the Subject, (4) Encouragement of Student Participation, (5) Rapport with Students, (6) Fairness in Grading, (7) Timeliness in Providing Feedback, (8) Organization of Class, (9) Adequacy of Textbook and Other Learning Materials, and (10) Instructor's Preparation for Class. The authors of this paper contend that these ten factors are equally relevant to the evaluation of instructors in online and on-campus classes. However, the specific instructor characteristics and behaviors students consider when they assign ratings differ significantly between online and on-campus classes.

Because of the lack of face-to-face contact between students and the instructor during regularly scheduled class meetings, online students tend to base evaluations on the frequency and quality of written communication, especially individual communication (e.g., replies to e-mail messages). In addition, the "Internet culture" conditions users to expect rapid feedback/response to questions, extensive/accurate information, and opportunities for real-time interaction with Web sites and individuals. Thus, students in online classes, many of whom are experienced Internet users, may demand a higher level of performance from online faculty. Students may judge an instructor as ineffective based on performance expectations that they don't apply to on-campus faculty.

This paper provided a number of suggestions to help online faculty adapt their teaching style to meet the differential demands/expectations of online students. Though empirical research is needed to assess the effective- 
ness of these suggestions, the authors believe that online faculty should experiment these suggestions if they want to improve their student evaluation results.

In conclusion, the authors believe that the different requirements/expectations for online teaching identified in this paper necessitate additional training, assistance (e.g., editorial support), and resources (e.g., funds to provide home computing resources) for online faculty. In addition, many factors outside the control of faculty can affect instructor performance and students evaluations of teaching effectiveness in online classes. Instructors need to be aware of these factors. They should also be concerned with the ability of students to differentiate between ineffective teaching and other uncontrollable factors such as technology failures. While there are many ways to help students identify these factors, it is largely the responsibility of instructors to manage student expectations related to online teaching performance.

\section{References}

1. Faurer, J. C. (2000). Managing a Ripple in the New Wave of Education Initiatives: Validity of Assessment. Mountain Plains Journal of Business and Economics, Vol. 1, available online at http://www.mountainplains.org/articles/mpa5.htm

2. Sheehan, E. P. and T. DuPrey (1999). Student Evaluations of University Teaching. Journal of Instructional Psychology, Vol. 26, Issue 3, September 1999.

3. U.S. Department of Education, National Center for Education Statistics. Distance Education at Postsecondary Education Institutions: 1997-98. NCES 2000-013, by Laurie Lewis, Kyle Snow, Elizabeth Farris, Douglas Levin. Bernie Greene, project officer. Washington, DC: 1999. 